\title{
Implementasi Deteksi Warna Pada Game Finding Color Menggunakan Ekstraksi Fitur Warna dan Fuzzy Decision Tree
}

\author{
http://dx.doi.org/10.28932/jutisi.v6i1.2388
}

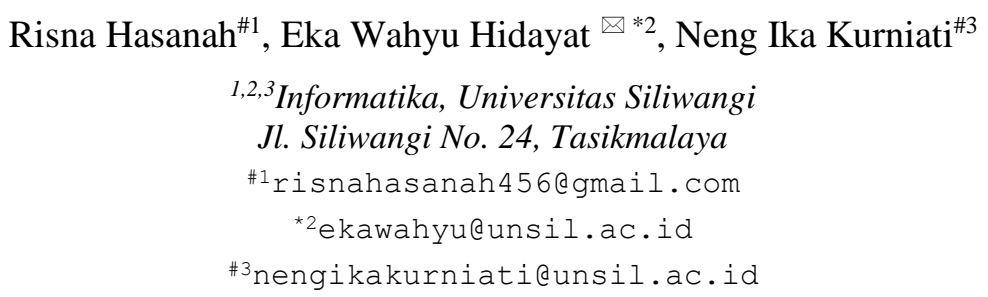

Abstract - Recognizing color is an ability that must be trained from an early age. But the ability to recognize color in early childhood is still low. One of the most preferred media by children is games. Android mobile games have the advantage of providing interactive multimedia, challenges, and rewards. Finding Color games can be used to help children play actively in exploring and observing colors in the surrounding environment because they can detect colors using the camera. The stages in color detection in games are feature extraction and color classification. Color feature extraction will get the color value at the selected pixel coordinates on the screen. The color classification uses fuzzy decision tree ID3. The test results of the application of color feature extraction produce an accuracy value of $100 \%$. The fuzzy decision tree classification is evaluated using a confusion matrix, resulting in an accuracy value in outdoor light conditions of $94.4 \%$. There is an increase of $4.4 \%$ compared to indoor conditions.

Keywords- Color Detection; Color Feature Extraction; Fuzzy Decision Tree; Game; Mobile Android

\section{Pendahuluan}

Mobile games kini menjadi jenis game yang paling populer karena dapat diakses dengan mudah dan terbilang murah dibandingkan jenis game lainnya [1]. Hal tersebut menjadikan mobile games memiliki banyak peminat dan sangat menarik untuk dikembangkan. Pada ranah pendidikan, game edukasi (edugames) memperoleh minat yang tinggi berdasarkan potensi yang dimiliki untuk memberikan dampak positif dalam proses belajar. Permainan pengenalan warna untuk anak usia dini banyak digunakan untuk membantu anak dalam mengamati, mempelajari dan mengingat beragam jenis warna. Kemampuan mengenali warna merupakan salah satu hal penting dan dasar untuk dikembangkan pada anak usia dini. Akan tetapi, kemampuan mengenali warna pada anak usia dini masih rendah [2], meskipun telah dilakukan pembelajaran dengan alat peraga [3], dengan aplikasi berbasis mobile android [4][5], anak masih kesulitan untuk membedakan warna misalnya anak didik kesulitan membedakan antara warna merah dengan oranye dan warna biru dengan hijau.

Berdasarkan permasalahan tersebut perlu dibuat suatu media pembelajaran berupa alat peraga berbasis digital dalam bentuk mobile game untuk membantu anak usia dini belajar warna dengan mempertimbangkan kemampuan kognitif anak dalam hal pengamatan secara visual yaitu menggunakan kamera. Namun hingga kini belum tersedia mobile game edukasi pengenalan warna menggunakan deteksi warna oleh kamera. Hal tersebut mendasari peneliti untuk membuat mobile game edukasi Finding Color yang dapat digunakan sebagai media pengenalan warna untuk anak usia dini. Game Finding Color menggunakan akses ke kamera sehingga anak dapat mengeksplorasi warna-warna di lingkungan sekitarnya dengan memberikan pertanyaan berupa nama warna secara acak, kemudian anak diharuskan menemukan warna tersebut di lingkungan sekitarnya dalam waktu yang ditentukan. Dengan begitu, anak dapat termotivasi untuk bergerak aktif dalam mencari warna di sekitar.

Pengenalan warna menggunakan kamera pada game Finding Color melalui suatu proses yaitu deteksi warna. Sehingga dibutuhkan metode pengolahan citra untuk menangkap nilai warna melalui kamera. Metode yang dipilih yaitu ekstraksi fitur warna yang bertujuan untuk mengenali warna berdasarkan nilai variable RGB (Red Green Blue) yang didapatkan pada koordinat layar (pixel) yang dipilih oleh pengguna. Selain itu, dengan sangat beragamnya jenis warna yang dapat dikenali oleh sensor kamera, sedangkan tingkat pengenalan warna pada anak usia dini masih terbatas, maka perlu dilakukan klasifikasi warna sehingga sistem dapat mengelompokkan jenis warna 
menjadi kelompok yang lebih sederhana dan terbatas. Decision tree merupakan pendekatan yang sangat populer dan praktis dalam machine learning untuk menyelesaikan permasalahan klasifikasi. Decision tree menggunakan himpunan aturan IF...THEN melalui proses dalam pembentukan pohon keputusan yaitu mengubah bentuk data (tabel) menjadi model pohon (tree) kemudian mengubah model pohon tersebut menjadi aturan (rule) [6]. Metode klasifikasi warna yang digunakan adalah jenis dari decision tree yaitu fuzzy decision tree. Fuzzy decision tree memanfaatkan teori himpunan fuzzy untuk menggambarkan tingkat keterhubungan suatu atribut, sedangkan untuk proses pembentukan pohon keputusan menggunakan proses induksi decision tree. Sehingga tahapan fuzzy decision tree memiliki perbedaan dengan tahapan logika fuzzy. Fuzzy decision tree dipilih mempertimbangkan karakteristik variable HSV yang digunakan pada proses klasifikasi yaitu merupakan nilai konitnu, bukan merupakan nilai benar atau salah namun memiliki nilai atribut berupa angka berkelanjutan sampai batas tertentu. Sehingga nilai atribut tersebut perlu dilakukan penggolongan kriteria ke dalam beberapa kriteria/range. Pembagian kriteria tersebut digambarkan menggunakan himpunan fuzzy. Himpunan fuzzy dinilai tepat untuk menggambarkan kriteria HSV karena himpunan fuzzy dikembangkan untuk menangkap ambiguitas, sedangkan penentuan HSV atau warna termasuk sebagai salah satu permasalahan ambiguitas. Proses induksi pohon keputusan merupakan proses penentuan urutan variable yang diterapkan pada pohon keputusan yaitu menggunakan algoritma ID3. Algoritma ID3 menggunakan nilai entropy dan information gain dari suatu atribut untuk menentukan urutan variabel pohon keputusan.

Masalah yang dikaji dalam penelitian ini adalah bagaimana implementasi deteksi warna objek menggunakan ekstraksi fitur warna dan klasifikasi warna menggunakan fuzzy decision tree algoritma ID3 pada game Finding Color. Tujuan dari penelitian ini adalah mengimplementasikan deteksi warna objek menggunakan ekstraksi fitur warna dan klasifikasi warna menggunakan fuzzy decision tree pada game Finding Color. Serta mendapatkan persentase tingkat keberhasilan dari proses ekstraksi fitur dan akurasi proses klasifikasi warna.

Hasil akhir yang diharapkan dari penelitian ini yaitu sebuah game Finding Color yang memiliki kemampuan untuk mendeteksi warna dengan menerapkan ekstraksi fitur warna dan fuzzy decision tree yang akurat. Dengan dibuatnya game Finding Color diharapkan dapat membantu proses pembelajaran anak dalam mengenali warna dengan bantuan perangkat digital yang dapat dimainkan secara interaktif.

\section{LANDASAN TEORI}

\section{A. Game Edukasi}

Pada ranah pendidikan, game edukasi (edugames) memperoleh minat yang tinggi berdasarkan potensi yang dimiliki untuk memberikan dampak positif dalam proses belajar. Game edukasi merupakan permainan yang dikemas untuk merangsang daya pikir termasuk meningkatkan konsentrasi dan menyelesaikan masalah [7]. Game edukasi mempunyai fungsi dan manfaat positif bagi anak, di antaranya yaitu anak dapat mengenal teknologi komputer, pelajaran untuk mengikuti pengarahan dan aturan, latihan memecahkan masalah dan logika, melatih saraf motorik dan keterampilan spasial, menjalin komunikasi anak-orangtua saat bermain bersama, serta memberikan hiburan. Bahkan, bagi pasien tertentu, permainan game dapat digunakan sebagai terapi penyembuhan [8].

\section{B. Warna}

Warna secara fisik mengacu pada sifat tekstur objek yang memungkinkannya untuk merefleksikan atau menyerap bagian-bagian tertentu dari insiden cahaya di atasnya. Aspek psikologis warna ditandai oleh sensasi visual yang dialami ketika cahaya dari frekuensi atau panjang gelombang tertentu terjadi pada retina. Sehingga cahaya dengan panjang gelombang yang sedikit berbeda memberikan dampak yang sangat berbeda [9].

\section{1) Deteksi Warna}

Deteksi warna bertujuan untuk mendeteksi adanya warnawarna tertentu sehingga dapat menentukan kelas warna piksel dalam citra yang diberikan [10]. Secara umum, warna pada gambar yang terdeteksi oleh sensor visual bergantung pada setidaknya tiga faktor utama dalam sebuah scene yaitu karakteristik refleksi fisik dari permukaan objek, kondisi pencahayaan, dan parameter intrinsik kamera [11].

\section{2) Ekstraksi Fitur Warna}

Fitur warna merupakan fitur yang menggabungkan informasi warna dalam deskripsi gambar. Sehingga ekstrasi fitur warna merupakan pengolahan citra yang dilakukan dengan cara menghitung jumlah titik atau pixel yang ada pada citra untuk memperoleh nilai RGB [12].

\section{Fuzzy decision tree}

Fuzzy decision tree memanfaatkan teori himpunan fuzzy untuk menggambarkan tingkat keterhubungan suatu atribut. Sehingga tahapan fuzzy decision tree berbeda dengan logika fuzzy. Fuzzy decision tree merupakan perpanjangan dari pohon keputusan klasik dan metode yang efektif untuk mengekstraksi pengetahuan dalam masalah klasifikasi yang tidak pasti. Ini menerapkan teori himpunan fuzzy untuk mewakili kumpulan data dan menggabungkan penanaman pohon dan pemangkasan untuk menentukan struktur pohon [13].

Proses induksi pohon keputusan fuzzy yang disarankan di sini terdiri dari langkah-langkah berikut [14]:

(1) Fuzzifikasi data pelatihan.

(2) Induksi fuzzy decision tree. 
(3) Mengubah pohon keputusan menjadi seperangkat aturan.

(4) Menerapkan aturan fuzzy tersebut untuk klasifikasi.

\section{Algoritma ID3}

Algoritma ID3 merupakan tahapan untuk menentukan fuzzy entropy dan information gain dari suatu atribut pada pohon keputusan sehingga dapat ditentukan atribut mana yang merupakan akar (root) ataupun daun (leaf). Berikut gambar 1 berisi flowchart algortima decision tree ID3.

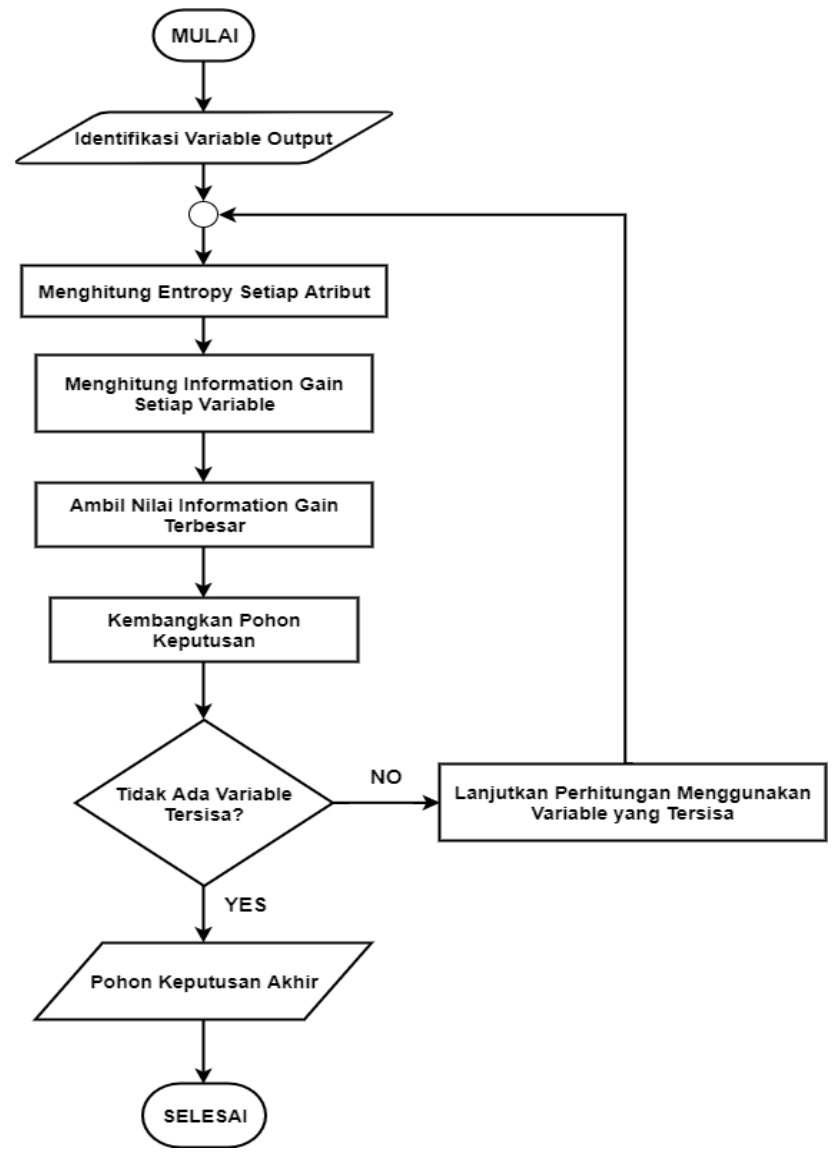

Gambar 1. Flowchart algoritma decision tree ID3

Gambar 1 berisi flowchart tahapan algoritma ID3 terdiri dari proses iterasi dengan perhitungan nilai entropy dan information gain pada himpunan data fuzzy, terdapat penyesuaian rumus untuk menghitung nilai entropy untuk atribut dan information gain karena adanya ekspresi data fuzzy. Untuk menentukan fuzzy entropy menggunakan persamaan 1 dan information gain menggunakan persamaan 2 sebagai berikut

$$
H_{f}(S, A)=-\sum_{i=1}^{C} \frac{\sum_{j}^{N} \mu_{i j}}{S} \log _{2} \frac{\sum_{j}^{N} \mu_{i j}}{S}
$$

$$
G_{f}(S)=H_{f}(S)-\sum_{v \subseteq A}^{N} \frac{\left|S_{v}\right|}{|S|} * H_{f}\left(S_{v}, A\right)
$$

Pada persamaan 1 dan 2 di atas dengan $\mu$ ij adalah nilai keanggotaan dari pola ke-j untuk kelas ke-i. H_f $(S)$ menunjukkan entropy dari himpunan $S$ dari data pelatihan pada node (A). $|S v|$ adalah ukuran dari subset $S v \subseteq S$ dari data pelatihan $x j$ dengan atribut v. $|S|$ menunjukkan ukuran dari himpunan $S$ [14].

\section{METODOLOG}

Metodologi penelitian yaitu kesatuan metode untuk memecahkan masalah secara logis dan sistematis serta dukungan dari data-data yang valid. Alur yang digunakan dalam penelitian ini adalah menggunakan kerangka penelitian berupa diagram alur pada gambar 2 sebagai berikut :

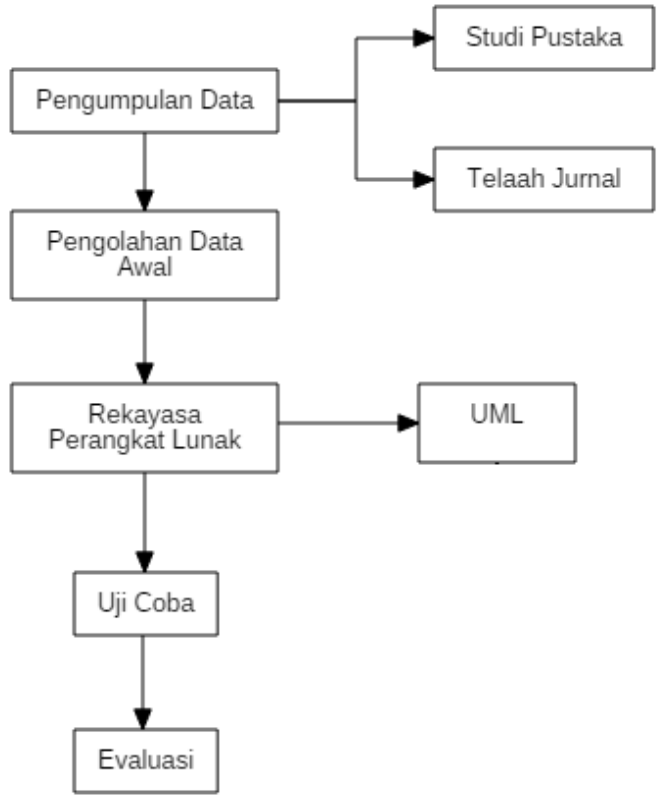

Gambar 2. Metodologi penelitian

\section{A. Pengumpulan Data}

Pengumpulan data yang bertujuan untuk mengumpulkan data dan bahan yang mendukung dan digunakan dalam penelitian dan pembuatan game edukasi ini. Menggunakan dua metode yaitu studi pustaka dan telaah jurnal. Dalam metode studi pustaka yaitu bersumber dari buku dan jurnaljurnal penelitian terkait dan menjadikannya sebagai referensi dalam penelitian.

\section{B. Pengolahan Data Awal}


Tahap pengolahan data awal yaitu pembentukan himpunan fuzzy dan klasifikasi warna untuk membentuk aturan fuzzy decision tree menggunakan algoritma ID3. Klasifikasi warna menggunakan pemodelan warna HSV.

\section{Rekayasa Perangkat Lunak}

Tahap rekayasa perangkat lunak dilakukan sebagai proses pembuatan game menggunakan metode UML, dimulai dengan melakukan analisis konseptual, pengidentifikasian aktor, penyusunan diagram, dan sebagainya sehingga hasil yang diperoleh yaitu sebuah game Finding Color.

\section{Uji Coba}

Uji coba yaitu kegiatan pengujian Game Finding Color untuk mendapatkan hasil deteksi warna pada Game, dan diterapkan pada dua tahap yaitu pada ekstraksi fitur dan klasifikasi fuzzy decision tree. Uji Coba dilakukan dengan menggunakan confusion matrix untuk menghasilkan persentase akurasi pada proses deteksi warna dan klasifikasi dengan fuzzy decision tree pada game.

\section{E. Evaluasi}

Evaluasi yaitu untuk menilai hasil dari penelitian yang telah dilakukan, dengan membandingkan keberhasilan yang dicapai dengan keberhasilan yang diharapkan. Peroses ini kemudian dilanjutkan dengan pengidentifikasian faktorfaktor yang berpengaruh pada kegagalan dan keberhasilan pada game Finding Color.

\section{IV.PERANCANGAN}

\section{A. Analisis Konseptual}

Menggambarkan proses kegiatan yang akan diterapkan dalam aplikasi dan menjelaskan kebutuhan yang diperlukan sistem agar sistem dapat berjalan dengan baik. Kebutuhan fungsional juga bersisi informasi apa saja yang harus tersedia dan dihasilkan sistem. Berikut hasil analisis konseptual game edukasi pengenalan warna berdasarkan perbandingan antara cara konvensional dan digital.

\section{1) Cara Konvensional}

Guru memberikan tugas kepada murid untuk menemukan 1 (satu) warna dari sekumpulan warna pada media belajar mewarnai. Murid menunjuk sesuai warna yang diminta oleh guru. Guru memberikan penilaian terhadap hasil pengerjaan tugas. Guru memberikan nilai jika jawaban murid benar dan memberikan koreksi apabila jawaban yang diberikan oleh murid salah.

\section{2) Cara Digital}

Anak menggunakan sistem game Finding Color pada perangkat mobile android. Sistem memiliki fungsi utama yaitu untuk deteksi warna sehingga sistem terlebih dahulu mengaktifkan akses kamera dengan ijin pengguna sehingga dapat digunakan untuk mencari warna yang ditugaskan. Sistem menangkap koordinat warna yang ditunjuk oleh pengguna dan disimpan sebagai jawaban. Untuk mendapatkan nilai warna berdasarkan jawaban pengguna maka dilakukan proses ekstraksi fitur warna. Nilai yang dihasilkan berupa nilai RGB (Red Green Blue). Untuk mengenali warna yang dimaksud oleh pengguna, terlebih dahulu sistem melakukan konversi RGB ke HSV. Nilai HSV (Hue Saturation Value) digunakan pada sistem karena memiliki kemiripan dengan sistem penglihatan manusia. Sistem menggolongkan beragam warna menjadi 9 warna dengan menggunakan proses klasifikasi. Proses klasifikasi warna dibentuk menggunakan fuzzy decision tree dengan algoritma ID3. Selain melakukan proses Finding Color, game ini juga dapat di custom oleh user untuk melakukan pengaturan suara dan informasi mengenai warna maupun aplikasi melalui pengaturan dan info.

\section{B. Unified Modelling Language (UML)}

Tahap perancangan aplikasi menggunakan pemodelan UML untuk menghasilkan rancangan sistem berbentuk diagram sebagai berikut:

\section{1) Use Case Diagram}

Use Case Diagram yang digambarkan pada gambar 3 berisi alur fungsi yang diharapkan dari sebuah sistem.

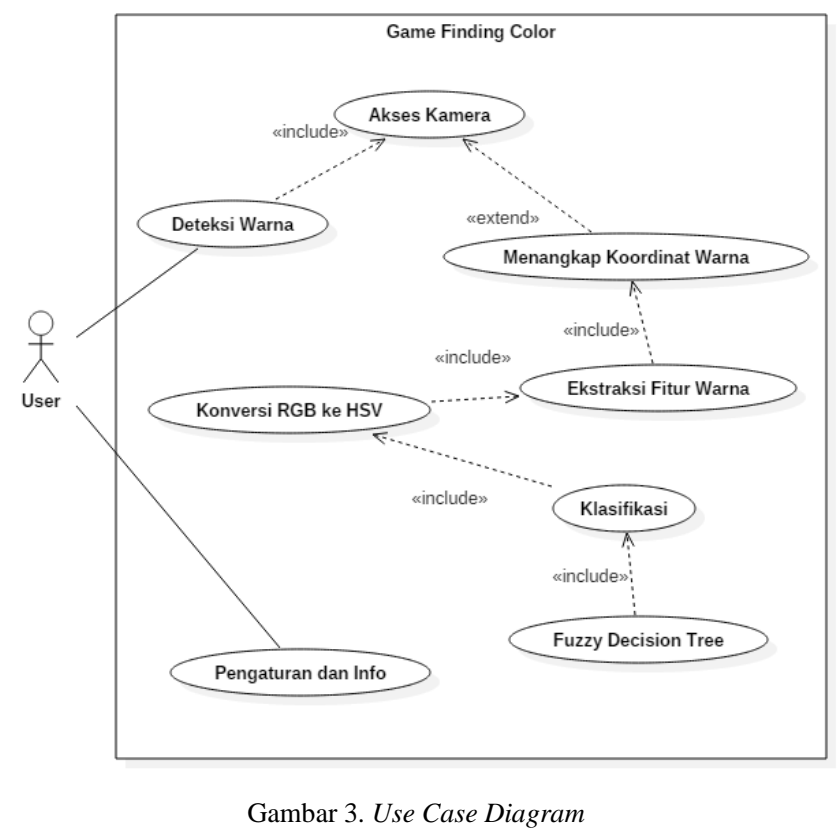

Gambar 3 berisi use case diagram yang menggambarkan proses pengenalan warna pada game Finding Color menggunakan kamera mobile. Tahap pertama untuk melakukan deteksi warna yaitu melalui akses kamera. Setelah user memberikan ijin akses kamera, maka sistem dapat menjalankan preview kamera dan menangkap titik koordinat warna yang dipilih oleh user. Berdasarkan titik pixel tersebut diperoleh nilai warna RGB melalui proses ekstraksi fitur warna. Pada proses klasifikasi menggunakan nilai warna HSV sehingga sedangkan nilai yang dihasilkan 
pada ekstraksi fitur warna yaitu RGB, maka terlebih dahulu dilakukan proses konversi nilai RGB menjadi HSV. Setelah diperoleh nilai HSV, sistem melakukan proses klasifikasi fuzzy decision tree dan menampilkan hasil klasifikasi warna. Menu pengaturan dan info berisi pengaturan suara dan info tentang aplikasi game Finding Color.

\section{2) Sequence Diagram}

Sequence diagram pada Gambar 4 menggambarkan interaksi pada beberapa entitas dalam sistem, termasuk pesan yang digunakan saat interaksi. Semua pesan dituliskan berdasarkan urutan dari eksekusi.

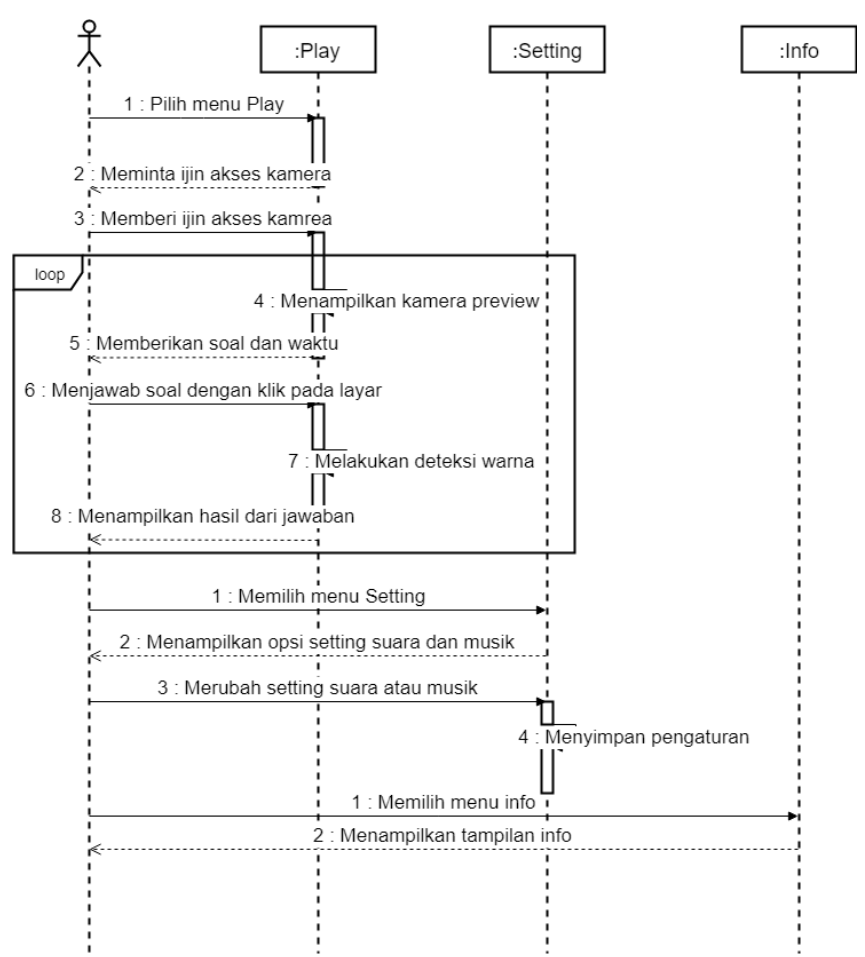

Gambar 4. Sequence Diagram

\section{3) Activity Diagram}

Activity diagram pada Gambar 5 menggambarkan aktivitas yang terjadi dalam sistem beserta urutannya berdasarkan use case yang telah ditentukan.

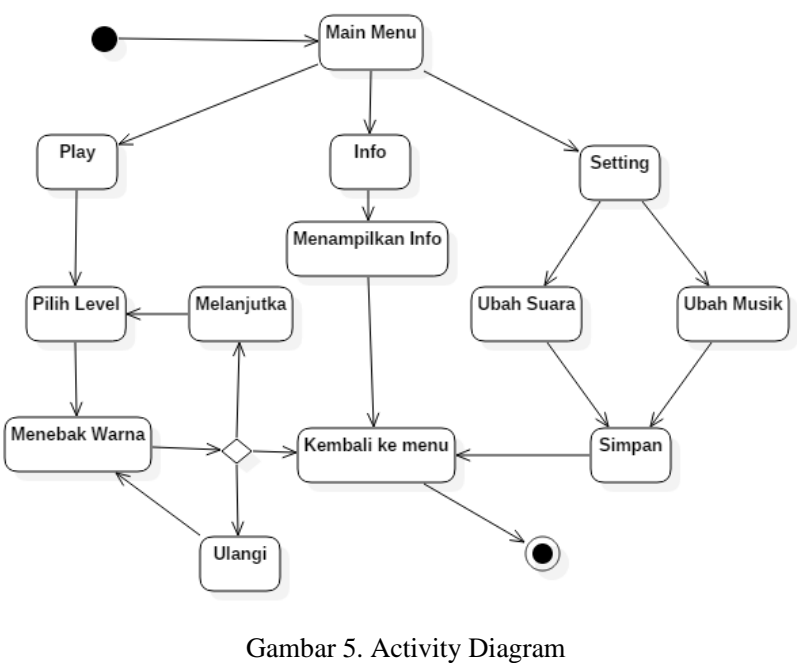

\section{4) Arsitektur Sistem}

Arsitektur sistem pada Gambar 6 mendefinisikan komponen-komponen pada sistem yang lebih spesifik secara terstruktur diantaranya yaitu hardware yang digunakan oleh sistem dan bagaimana user menggunakan perangkat tersebut.

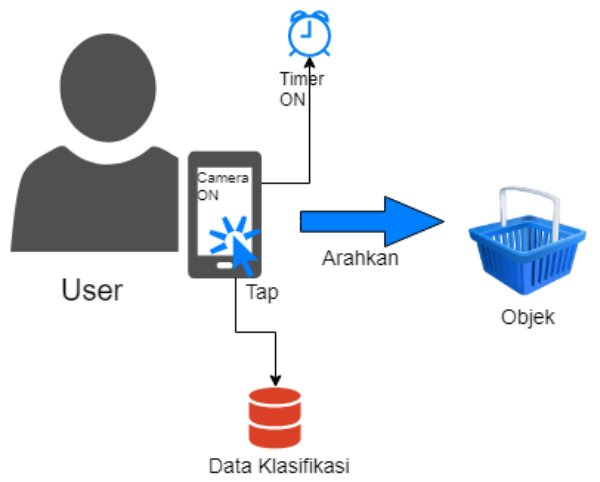

Gambar 6. Arsitektur Sistem

\section{Perancangan Antar Muka}

Perancangan antar muka merupakan bentuk visual atau gambaran untuk menghasilkan desain visual dari sistem.

\section{1) Antar Muka Menu Utama dan Permainan}

Halaman menu utama dan halaman permainan (game) digambarkan pada Gambar 7. 

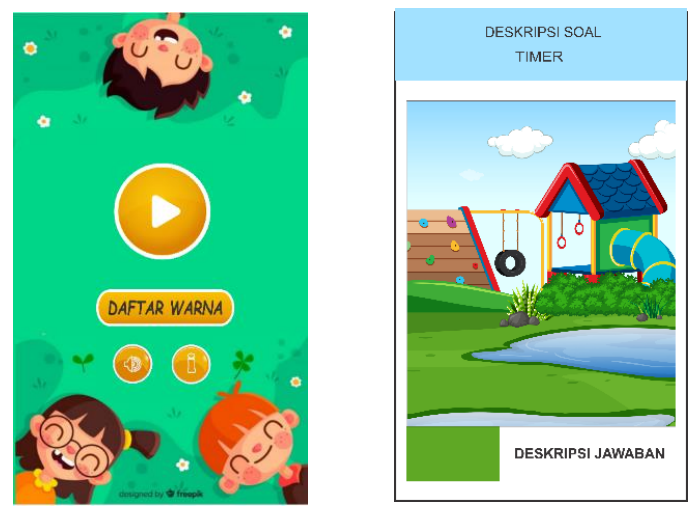

Gambar 7. Desain Antar Muka Menu Utama dan Permainan

Pada Gambar 7 bagian kiri berisi menu utama pada sistem. Halaman utama berisi menu mulai permainan, daftar warna untuk dipelajari, pengaturan suara dan info. Sedangkan halaman permainan terdapat pada bagian kanan. berisi deskripsi dan kamera preview. Area deskripsi terdiri dari 2 (dua) bagian yaitu deskripsi soal dan deskripsi jawaban. Deskripsi soal berisi nama warna yang harus dicari dan waktu yang tersisa (timer). Kamera preview menunjukkan gambar yang ditangkap oleh kamera mobile. Sedangkan pada area deskripsi jawaban berisi tampilan warna dan nilai pixel yang dipilih oleh user, nilai HSV, dan output warna berdasarkan hasil klasifikasi fuzzy decision tree.

\section{2) Antar Muka Hasil Jawaban Benar dan Gagal}

Apabila jawaban yang diberikan user adalah benar atau user gagal dalam menjawab soal yaitu saat waktu yang diberikan pada satu sesi (30 detik) berakhir, maka ditampilkan halaman hasil berdasarkan Gambar 8.
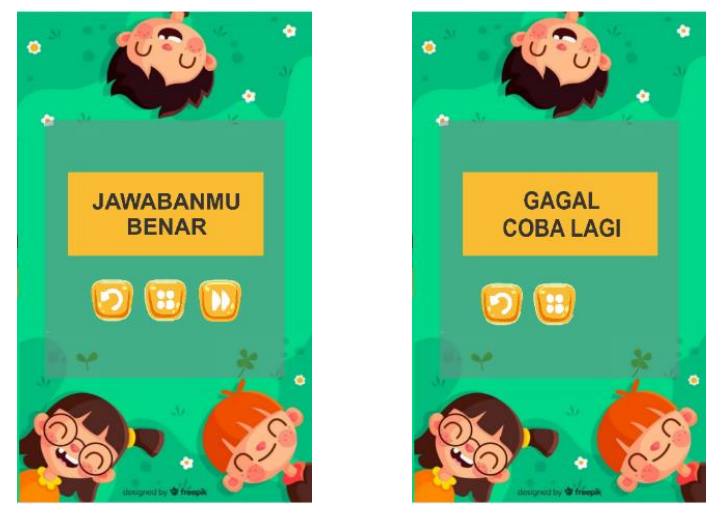

Gambar 8. Antar Muka Jawaban Benar dan Gagal

Pada Gambar 8 terdapat 2 (dua) halaman berisi pesan yang berbeda yaitu apabila jawaban benar, user dapat beralih ke soal selanjutnya, mencoba soal yang sama lagi, dan kembali ke halaman utama. Sedangkan jika gagal menjawab benar, maka user hanya dapat mengulangi soal yang sama atau kembali ke halaman utama.

\section{HASIL PENELITIAN DAN PEMBAHASAN}

\section{A. Pembentukan Himpunan Fuzzy}

Tahap membentuk himpunan fuzzy dan penentuan derajat keanggotaan dari crisp input pada sebuah himpunan fuzzy. Pembentukan himpunan fuzzy baik variable input maupun variable output dibagi menjadi satu atau lebih himpunan fuzzy. Variable yang digunakan yaitu HSV (Hue Saturation Value) yang memiliki himpunan semesta.

TABEL I

HIMPUNAN SEMESTA VARIABEL HSV

\begin{tabular}{|c|c|}
\hline Variabel & Himpunan Semesta \\
\hline $\mathrm{H}$ & {$[0,360]$} \\
\hline $\mathrm{S}$ & {$[0,100]$} \\
\hline $\mathrm{V}$ & {$[0,100]$} \\
\hline
\end{tabular}

Nilai himpunan semesta yang ditentukan pada tabel I merupakan nilai minimum dan maksimum dari setiap variabel ruang warna $\mathrm{HSV}$, yaitu variabel $\mathrm{H}$ (Hue) memiliki nilai maksimum 360, sedangkan variabel S (Saturation) dan $\mathrm{V}$ (Value) memiliki nilai maksimum 100. Berdasarkan himpunan semesta variable HSV yang disebutkan pada Tabel II, maka dibentuk fungsi keanggotaan fuzzy pada setiap masing-masing variabel $\mathrm{H}, \mathrm{S}$ dan $\mathrm{V}$ berdasarkan hasil pengamatan secara manual menggunakan pemetaan ruang warna HSV secara visual menghasilkan fungsi keanggotaan sebagai berikut:

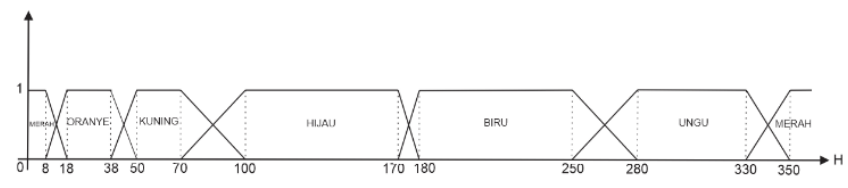

Gambar 9. Fungsi Keanggotaan Variabel H

Gambar 9 merupakan fungsi keanggotaan variable $\mathrm{H}$ menggambarkan dominasi warna dengan anggota sebanyak 6 (enam) yaitu merah, oranye, kuning, hijau, biru dan ungu. Jumlah anggota tersebut dibatasi warna dasar yang mudah dibedakan sebagai tahap awal pengenalan warna untuk anak usia dini.

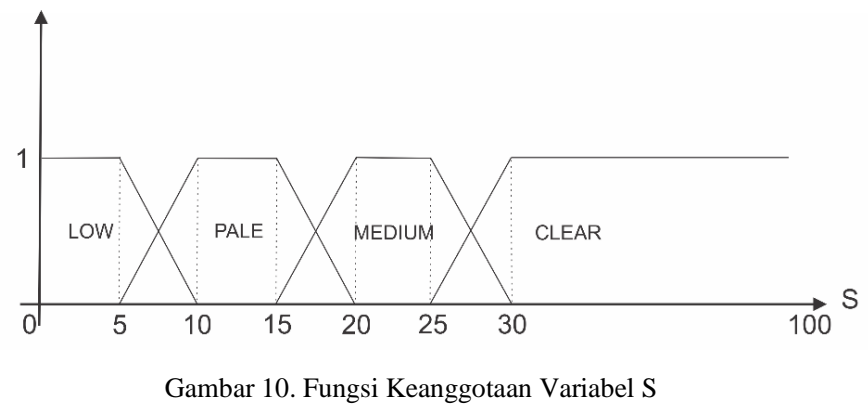


Gambar 10 merupakan fungsi keanggotaan variable $\mathrm{S}$ dengan anggota sebanyak 4 (empat) yaitu low, pale, medium, dan clear. Jumlah anggota tersebut menggambarkan kelompok tingkat kejelasan suatu warna. Semakin tinggi nilai S maka semakin jelas warna yang dihasilkan.

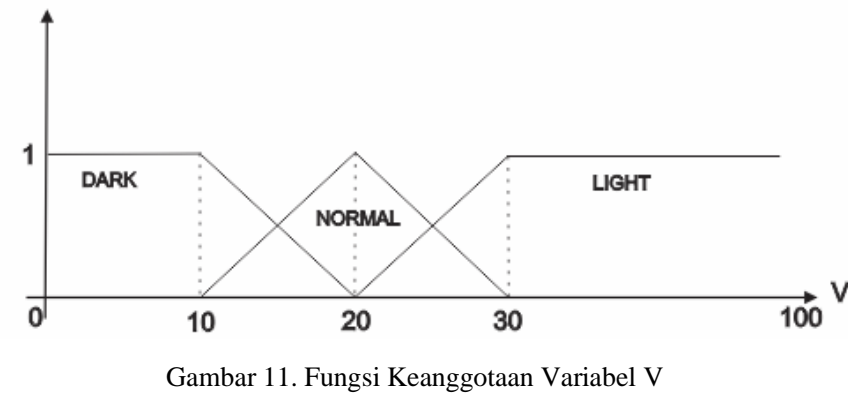

Gambar 11 merupakan fungsi keanggotaan variabel V menggambarkan tingkat warna putih dengan anggota sebanyak 3 (tiga) yaitu dark, normal dan light. Semakin tinggi nilai $\mathrm{V}$ maka warna tersebut semakin mendekati warna putih.

Untuk memudahkan identifikasi warna maka output warna ditentukan terlebih dahulu berdasarkan output warna yang diperoleh dari fungsi keanggotaan HSV menghasilkan Tabel II yang berisi identifikasi warna.

TABEL II

IDENTIFIKASI OUTPUT WARNA

\begin{tabular}{|c|c|c|}
\hline No. & Color Number $\boldsymbol{i}$ & Output $\boldsymbol{C}$ \\
\hline 1. & C1 & Hitam \\
\hline 2. & C2 & Abu-abu \\
\hline 3. & C3 & Putih \\
\hline 4. & C4 & Merah \\
\hline 5. & C5 & Oranye \\
\hline 6. & C6 & Kuning \\
\hline 7. & C7 & Hijau \\
\hline 8. & C 8 & Biru \\
\hline 9. & C 9 & Ungu \\
\hline
\end{tabular}

Tabel II menyebutkan sebanyak 9 (sembilan) jenis warna yang ditentukan sebagai output warna pada penelitian ini. Output warna ditentukan untuk membatasi warna yang dihasilkan melalui pengenalan warna oleh aplikasi dan memudahkan identifikasi warna sehingga penulisan atribut pada pohon keputusan yang terbentuk lebih sederhana.

\section{B. Fuzzy Entrophy, Information Gain dan Pohon Keputusan}

Menghitung entropy menggunakan persamaan 1 dan information gain menggunakan persamaan 2, sehingga dapat diperoleh urutan atribut ditempatkan dari root sampai ke leaf berdasarkan nilai information gain terbesar. Pada tabel III ditampilkan hasil iterasi pertama menggunakan fuzzy decision tree ID3.
TABEL III

ANALISIS NODE 1

\begin{tabular}{|c|c|c|c|c|}
\hline Node & Atribut & Nilai & Entropy & $\begin{array}{l}\text { Information } \\
\text { Gain }\end{array}$ \\
\hline \multirow[t]{16}{*}{1} & \multirow[t]{7}{*}{$\mathrm{H}$} & Merah & 1,855389 & \\
\hline & & Oranye & 1,855389 & \\
\hline & & Kuning & 1,855389 & \\
\hline & & Hijau & 1,855389 & \\
\hline & & Biru & 1,855389 & \\
\hline & & Ungu & 1,855389 & \\
\hline & & & & 0,861654 \\
\hline & \multirow[t]{5}{*}{$\mathrm{S}$} & Low & 1,584963 & \\
\hline & & Pale & 1,584963 & \\
\hline & & Medium & 2,595489 & \\
\hline & & Clear & 2,595489 & \\
\hline & & & & 0.793484 \\
\hline & \multirow[t]{4}{*}{$\mathrm{V}$} & Dark & 0 & \\
\hline & & Normal & 2,292481 & \\
\hline & & Light & 2.792481 & \\
\hline & & & & 1,022055 \\
\hline
\end{tabular}

Berdasarkan Tabel III diperoleh information gain terbesar yaitu sebesar 1,022055 pada atribut V. Sehingga atribut V menjadi node akar. Visualisasi pohon keputusan dengan atribut V sebagai root pada Gambar 12.

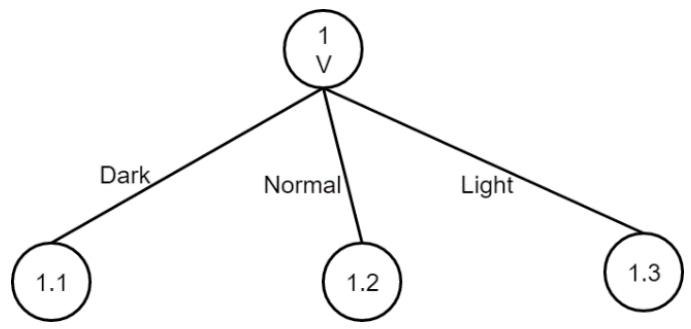

Gambar 12. Fuzzy decision tree ID3 Node 1

Gambar 12 berisi atribut V sebagai root memiliki 3 nilai yaitu Dark, Normal dan Light. Nilai atribut Dark membagi klasifikasi menjadi satu output yang sama yaitu Hitam/C1, sehingga perhitungan pada atribut Dark berakhir.

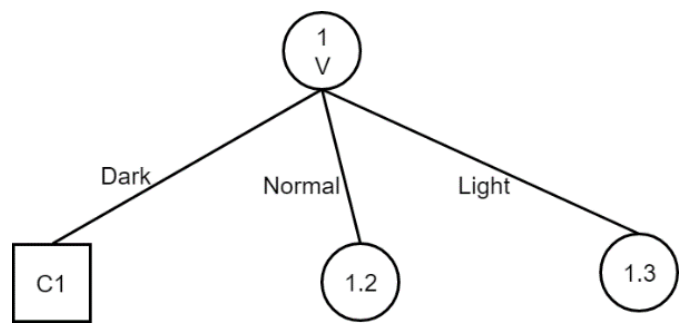

Gambar 13. Fuzzy decision tree ID3 Analisis Node 1.1

Gambar 13 menunjukkan node 1.1 (Dark) telah menghasilkan output warna, sehingga atribut Normal dan Light perlu dilakukan perhitungan untuk menentukan node cabang berdasarkan information gain terbesar. Perhitungan pertama pada node Normal menggunakan proses yang sama menggunakan atribut yang tersisa kecuali variable V. Tahap 
perhitungan entropi pada atribut Normal menghasilkan Tabel IV.

TABEL IV

ANALISIS NODE 1.2

\begin{tabular}{|c|c|c|c|c|}
\hline Node & Atribut & Nilai & Entropy & $\begin{array}{l}\text { Information } \\
\text { Gain }\end{array}$ \\
\hline \multirow[t]{12}{*}{1.2} & \multirow[t]{7}{*}{$\mathrm{H}$} & Merah & 1 & \\
\hline & & Oranye & 1 & \\
\hline & & Kuning & 1 & \\
\hline & & Hijau & 1 & \\
\hline & & Biru & 1 & \\
\hline & & Ungu & 1 & \\
\hline & & & & 1,292481 \\
\hline & \multirow[t]{5}{*}{$S$} & Low & 0 & \\
\hline & & Pale & 0 & \\
\hline & & Medium & 2,58496 & \\
\hline & & Clear & 2,58496 & \\
\hline & & & & 1 \\
\hline
\end{tabular}

Berdasarkan hasil perhitungan pada Tabel IV dapat diketahui nilai information gain terbesar yaitu pada atribut $\mathrm{H}$ sebesar 1,292481. Sehingga $\mathrm{H}$ menjadi node cabang dari nilai atribut Normal yaitu node 1.2.

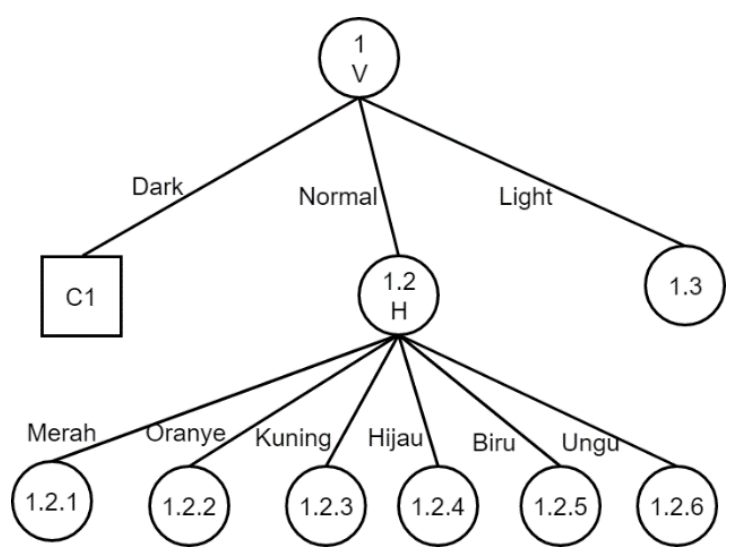

Gambar 14. Fuzzy decision tree ID3 Analisis Node 1.2

Pada Gambar 14 atribut $\mathrm{H}$ telah digunakan setelah V (root) sehingga atribut yang tersisa yaitu atribut S. Maka S ditempatkan setelah atribut $\mathrm{H}$ dan berakhir mencapai node leaf menghasilkan output warna.

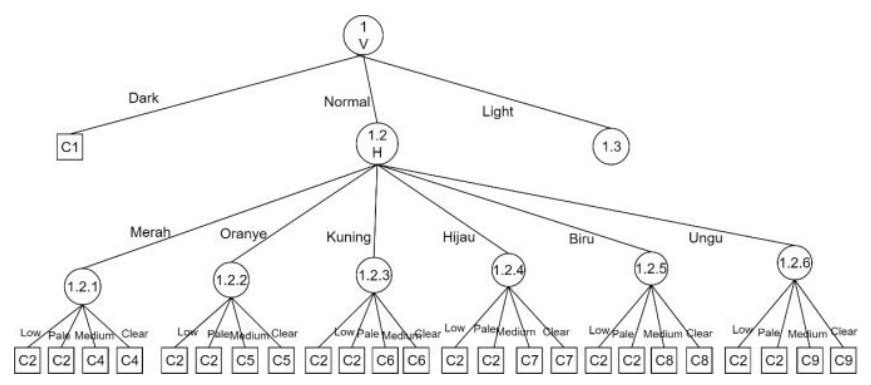

Gambar 15. Fuzzy decision tree ID3 Analisis Hasil Akhir Node 1.2

Gambar 15 berisi pohon keputusan nilai output dari atribut kecuali $\mathrm{H}=$ Light. Sehingga tahap selanjutnya yaitu menentukan atribut pada cabang dari atribut $\mathrm{V}=$ Light atau node 1.3. Tabel $\mathrm{V}$ menunjukkan hasil perhitungan iterasi ketiga pada atribut Light pada masing-masing atribut nilai dengan V merupakan Light.

TABEL V

ANALISIS NODE 1.3

\begin{tabular}{|c|c|c|c|c|}
\hline Node & Atribut & Nilai & Entropy & $\begin{array}{l}\text { Information } \\
\text { Gain }\end{array}$ \\
\hline \multirow[t]{12}{*}{1.3} & \multirow[t]{7}{*}{$\mathrm{H}$} & Merah & 1,5 & \\
\hline & & Oranye & 1,5 & \\
\hline & & Kuning & 1,5 & \\
\hline & & Hijau & 1,5 & \\
\hline & & Biru & 1,5 & \\
\hline & & Ungu & 1,5 & \\
\hline & & & & 1,292481 \\
\hline & \multirow[t]{5}{*}{$\mathrm{S}$} & Low & 0 & \\
\hline & & Pale & 0 & \\
\hline & & Medium & 0,430827 & \\
\hline & & Clear & 0,430827 & \\
\hline & & & & 1,5 \\
\hline
\end{tabular}

Berdasarkan Tabel V diketahui nilai gain terbesar yaitu pada atribut $\mathrm{S}$ sebesar 1,5. Sehingga $\mathrm{S}$ menjadi node cabang dari nilai atribut Light atau node 1.3. Pada atribut Low menghasilkan klasifikasi menjadi 1 yaitu Putih dan pada Pale menghasilkan 1 warna yaitu Abu-abu. Sehingga cabang pada atribut Low dan Pale node berakhir dan menghasilkan masing-masing 1 output warna.

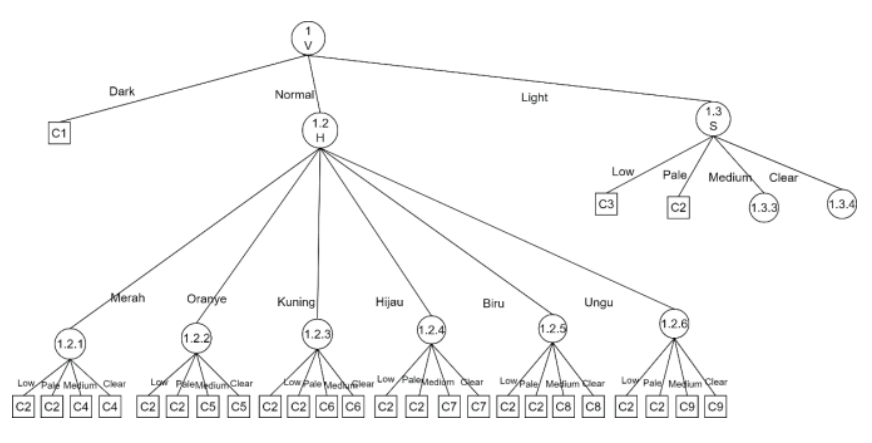

Gambar 16. Fuzzy decision tree ID3 Analisis Node 1.3

Gambar 16 memperlihatkan atribut $\mathrm{S}$ digunakan untuk node 1.3 , sehingga atribut yang tersisa yaitu $\mathrm{H}$. Selanjutnya ditempatkan atribut yang tersisa yaitu $\mathrm{H}$ pada node 1.3.3 dan 1.3.4 hingga mencapai node leaf dan menghasilkan output warna. Visualisasi pada Gambar 17 menampilkan hasil akhir pohon keputusan. 


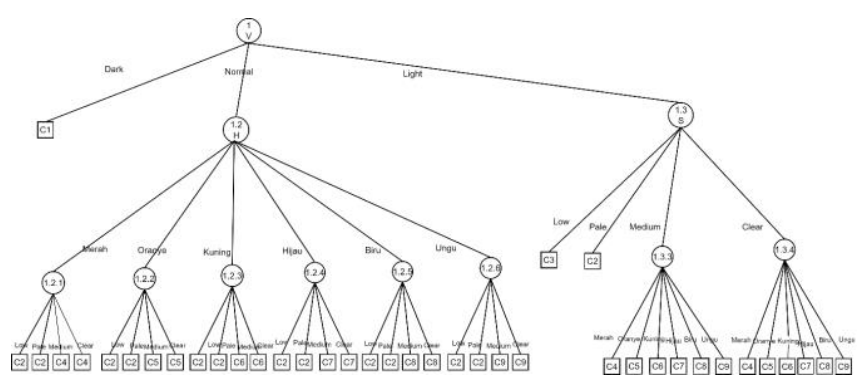

Gambar 17. Fuzzy decision tree Akhir

\section{Pembentukan Rule}

Tahap selanjutnya yaitu membentuk rule berdasarkan pohon keputusan yang telah dibuat. Tabel VI berisi aturan yang dihasilkan.

TABEL VI

ATURAN

\begin{tabular}{|l|}
\hline \multicolumn{1}{|c|}{ Rule } \\
\hline IF V dark THEN $C_{1}$ \\
\hline IF V normal AND H merah AND S low OR pale THEN $C_{2}$ \\
\hline IF V normal AND H merah AND S medium OR clear THEN $C_{4}$ \\
\hline IF V normal AND H oranye AND S low OR pale THEN $C_{2}$ \\
\hline IF V normal AND H oranye AND S medium OR clear THEN $C_{5}$ \\
\hline IF V normal AND H kuning AND S low OR pale THEN $C_{2}$ \\
\hline IF V normal AND H kuning AND S medium OR clear THEN $C_{\overline{6}}$ \\
\hline IF V normal AND H hijau AND S low OR pale THEN $C_{2}$ \\
\hline IF V normal AND H hijau AND S medium OR clear THEN $C_{7}$ \\
\hline IF V normal AND H biru AND S low OR pale THEN $C_{2}$ \\
\hline IF V normal AND H biru AND S medium OR clear THEN $C_{9}$ \\
\hline IF V normal AND H ungu AND S low OR pale THEN $C_{2}$ \\
\hline IF V normal AND H ungu AND S medium OR clear THEN $C_{9}$ \\
\hline IF V light AND S low THEN $C_{9}$ \\
\hline IF V light AND S pale THEN $C_{2}$ \\
\hline IF V light AND S medium OR clear AND H merah THEN $C_{4}$ \\
\hline IF V light AND S medium OR clear AND H oranye THEN $C_{5}$ \\
\hline IF V light AND S medium OR clear AND H kuning THEN $C_{\overline{6}}$ \\
\hline IF V light AND S medium OR clear AND H hijau THEN $C_{7}$ \\
\hline IF V light AND S medium OR clear AND H biru THEN $C_{9}$ \\
\hline IF V light AND S medium OR clear AND H ungu THEN $C_{9}$ \\
\hline
\end{tabular}
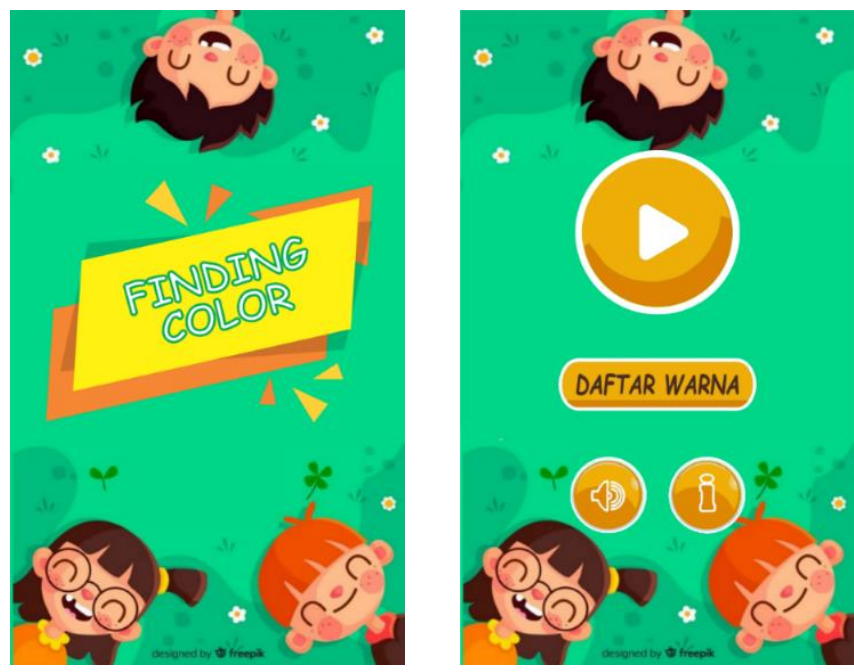

Gambar 18. Halaman splash screen dan halaman utama
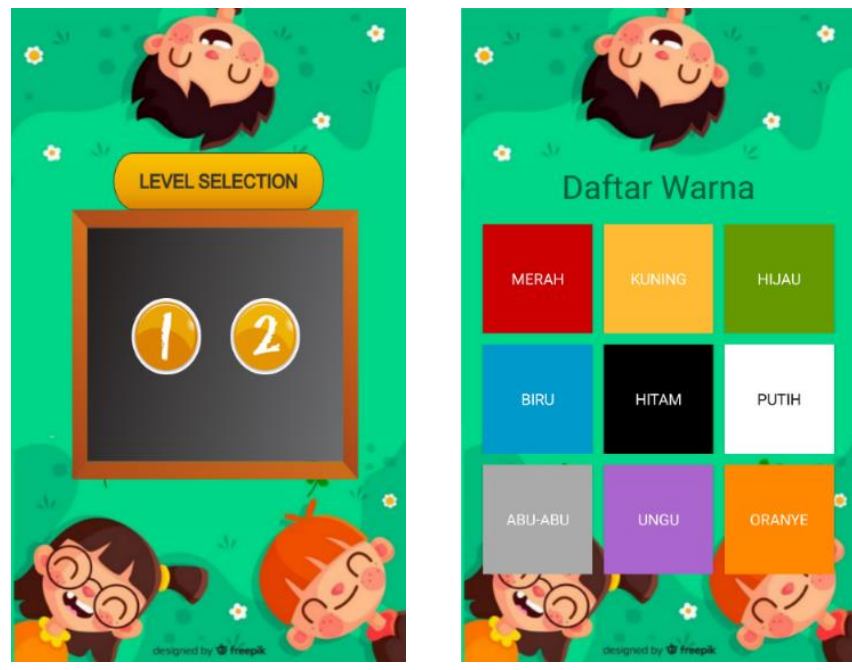

Gambar 19. Halaman level dan halaman daftar warna

\section{Implementasi Antar Muka}

Implementasi antar muka game Finding Color ditampilkan pada Gambar 18 sampai dengan gambar 22. 


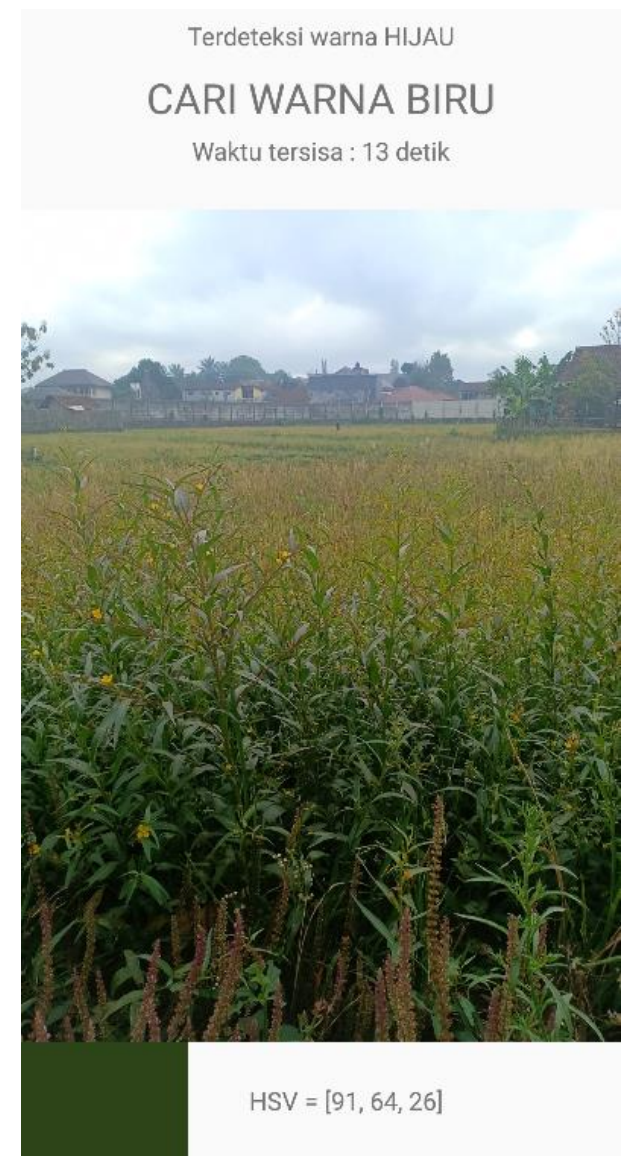

Gambar 20. Halaman permainan Finding Color
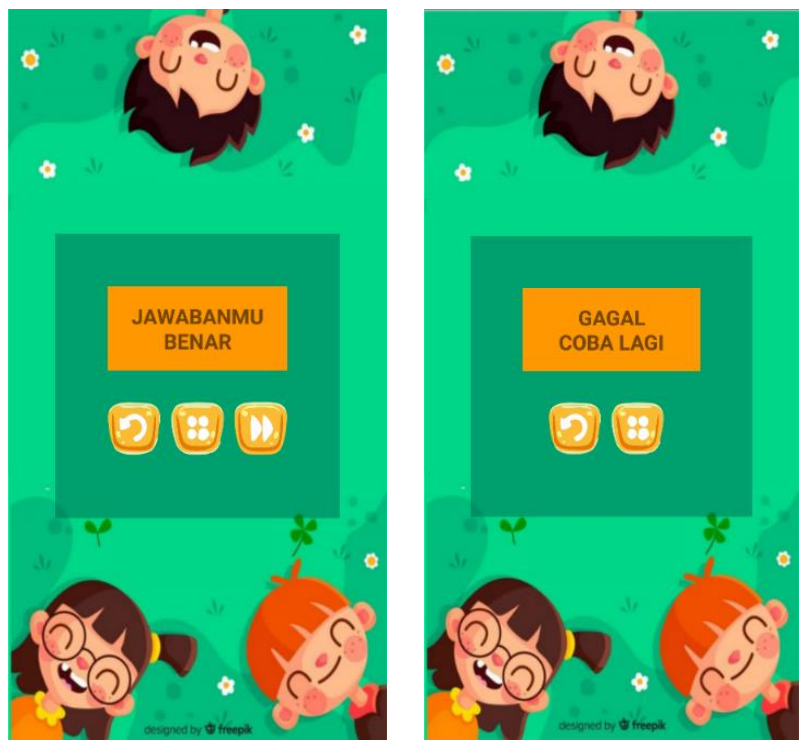

Gambar 21. Halaman hasil benar dan halaman hasil gagal
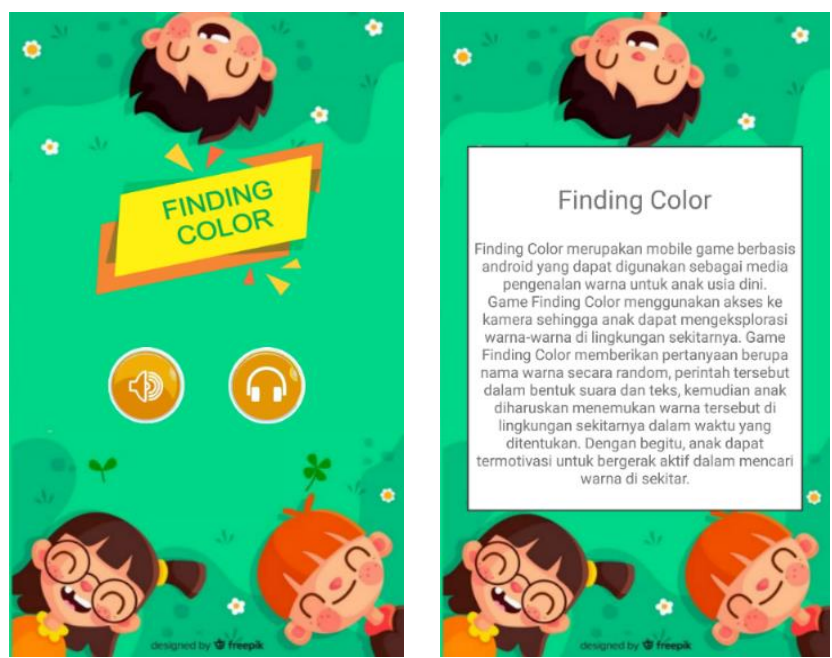

Gambar 22. Halaman pengaturan suara dan halaman info

\section{UJI COBA}

\section{A. Uji Coba Keberhasilan Ekstraksi Fitur Warna}

Uji coba ekstraksi fitur yaitu tahap untuk melakukan pengujian sehingga dapat diketahui persentase tingkat keberhasilan berdasarkan data yang diperoleh yaitu berupa koordinat titik pixel yang dipilih dengan nilai RGB pada pixel. Uji coba dilakukan menggunakan kamera mobile sebesar 16 megapixel pada 90 data uji pada 9 warna menghasilkan Tabel VII.

TABEL VII

\section{UJI COBA EKSTRASI FITUR WARNA}

\begin{tabular}{|l|c|c|c|}
\hline No. & Warna & Pengujian & Error \\
\hline 1. & Hitam & 10 & 0 \\
\hline 2. & Abu-abu & 10 & 0 \\
\hline 3. & Putih & 10 & 0 \\
\hline 4. & Merah & 10 & 0 \\
\hline 5. & Oranye & 10 & 0 \\
\hline 6. & Kuning & 10 & 0 \\
\hline 7. & Hijau & 10 & 0 \\
\hline 8. & Biru & 10 & 0 \\
\hline 9. & Ungu & 10 & 0 \\
\hline
\end{tabular}

\section{B. Uji Coba Klasifikasi Warna}

Uji coba klasifikasi dilakukan untuk mengukur tingkat akurasi yang diperoleh berdasarkan klasifikasi yang diterapkan. Uji coba dilakukan pada dua kondisi yaitu pada ruangan dan cahaya luar ruangan. Setiap kondisi menggunakan 90 data uji yang terbagi menjadi 9 output warna beranggotakan 10 data. Dilakukan perbandingan warna yang terdeteksi oleh kamera dan warna sesungguhnya dan dilakukan pengecekan menggunakan metode confusion matrik. Pengujian dilakukan di dalam ruangan yang memiliki dinding berwarna kuning dengan lampu menyala. Tabel VIII menunjukkan hasil pengujian klasifikasi warna. 
TABEL VIII

HASIL UJI COBA KLASIFIKASI PADA KONDISI CAHAYA RUANGAN

\begin{tabular}{|c|l|c|}
\hline \multirow{2}{*}{$\begin{array}{c}\text { Correct } \\
\text { Classification }\end{array}$} & \multicolumn{2}{|c|}{ Classified as } \\
\cline { 2 - 3 } & Predicted "+"” & Predicted "_." \\
\hline Actual "+" & 81 data (TP) & 9 data (FN) \\
\hline Actual "_"“ & 0 data (FP) & 0 data (TN) \\
\hline
\end{tabular}

$$
\begin{aligned}
& \text { Accuracy }=(\mathrm{TP}+\mathrm{TN}) / \text { Total data } \\
& \quad=(81+0) / 90 \\
& =81 / 90 \\
& \quad=0,9 \times 100 \% \\
& \quad=90 \%
\end{aligned}
$$

Misclassification Rate $=(\mathrm{FP}+\mathrm{FN}) /$ Total data

$=(0+9) / 90$

$=9 / 90$

$$
=0,1 \times 100 \%
$$$$
=10 \%
$$

Pengujian klasifikasi fuzzy decision tree pada game Finding Color juga dilakukan pada kondisi cahaya luar ruangan yaitu dengan sinar matahari sekitar jam 8 pagi menghasilkan Tabel IX.

TABEL IX

HASIL UJI COBA KLASIFIKASI PADA KONDISI CAHAYA LUAR RUANGAN

\begin{tabular}{|c|l|c|}
\hline \multirow{2}{*}{$\begin{array}{c}\text { Correct } \\
\text { Classification }\end{array}$} & \multicolumn{2}{|c|}{ Classified as } \\
\cline { 2 - 3 } & Predicted "+"” & Predicted "_." \\
\hline Actual "+" & 85 data (TP) & 5 data (FN) \\
\hline Actual "_"“ & 0 data (FP) & 0 data (TN) \\
\hline
\end{tabular}

$$
\begin{aligned}
& \text { Accuracy }=(\mathrm{TP}+\mathrm{TN}) / \text { Total data } \\
& \quad=(85+0) / 90 \\
& \quad=85 / 90 \\
& \quad=0,944 \times 100 \% \\
& \quad=94,4 \% \\
& \text { Misclassification Rate }=(\mathrm{FP}+\mathrm{FN}) / \text { Total data } \\
& \quad=(0+5) / 90 \\
& \quad=5 / 90 \\
& =0,056 \times 100 \% \\
& =5,6 \%
\end{aligned}
$$

Pengujian ekstraksi fitur warna berdasarkan Tabel VIII menggunakan 90 data menghasilkan tingkat keberhasilan $100 \%$. Hal tersebut menunjukan bahwa sistem berhasil mendapatkan nilai koordinat dan nilai RGB pada pixel yang dipilih tanpa menyebabkan error/invalid. Sedangkan tahap pengujian klasifikasi warna menggunakan fuzzy decision tree menghasilkan nilai akurasi pada Tabel X.

$$
\text { TABEL X }
$$

NILAI AKURASI KLASIFIKASI FUZZY DECISION TREE

\begin{tabular}{|c|c|}
\hline Cahaya Ruangan & Cahaya Luar Ruangan \\
\hline $90 \%$ & $94,4 \%$ \\
\hline
\end{tabular}

Berdasarkan Tabel $\mathrm{X}$ kondisi pencahayaan yang menghasilkan nilai akurasi terbaik adalah kondisi cahaya luar ruangan dengan akurasi $94,4 \%$. Peningkatan intensitas cahaya pada penelitian menyebabkan nilai akurasi yang dihasilkan lebih besar. Hal tersebut dikarenakan pencahayaan yang cukup dapat mendukung sistem dapat mengenali warna dengan baik.

Kelebihan dalam game Finding Color yaitu memanfaatkan akses kamera sehingga user dapat mengeksplorasi warna-warna yang terdapat di sekitar untuk melakukan deteksi warna.

Kekurangan dalam game Finding Color yaitu hasil deteksi warna sangat bergantung pada kondisi pencahayaan dan tekstur objek. Apabila pada kondisi pencahayaan kurang, maka warna akan terdeteksi sebagai warna yang lebih gelap. Tekstur objek yang kasar memiliki nilai pixel yang beragam meskipun objek tersebut memiliki satu warna dasar. Hal tersebut disebabkan oleh pantulan cahaya atau bayangan yang dihasilkan pada tekstur. Selain itu belum tersedia beberapa warna dasar yang lain, salah satunya warna cokelat.

\section{KESIMPULAN}

Game Finding Color dapat dimanfaatkan untuk membantu anak usia dini bermain secara aktif dalam mempelajari dan mengamati warna di lingkungan sekitar. Deteksi warna pada game dilakukan dalam dua tahap yaitu ekstraksi fitur dan klasifikasi warna. Ekstraksi fitur warna bertujuan untuk mendapatkan nilai warna pada koordiat pixel yang dipilih oleh user. Klasifikasi warna yang digunakan menerapkan pohon keputusan fuzzy decision tree ID3. Hasil uji penerapan ekstraksi fitur warna dengan 90 data menghasilkan tingkat keberhasilan 100\%. Sehingga dapat diketahui bahwa penerapan ekstraksi fitur warna pada sistem telah berhasil. Penerapan klasifikasi fuzzy decision tree telah dievaluasi menggunakan confusion matrix berhasil menyelesaikan permasalahan. Hal ini terbukti dari meningkatnya nilai akurasi pada kondisi pencahayaan yang lebih terang dibandingkan kondisi pencahayaan ruangan menggunakan 90 data uji. Hasil nilai akurasi terbaik pada kondisi cahaya luar ruangan yaitu sebesar 94,4\%. Adapun peningkatan nilai akurasi yaitu sebesar $4,4 \%$. Melihat hasil pengujian pada penelitian sebelumnya [15] dalam proses klasifikasi warna menggunakan pengolahan model warna HSV pada 6 jenis warna dengan pengujian 10 kali untuk masing-masing warna menghasilkan nilai error terkecil yaitu $10 \%$ dengan tingkat keberhasilan terbesar yaitu $90 \%$. Sehingga dapat diperoleh kesimpulan bahwa klasifikasi warna pada game Finding Color menggunakan ekstraksi fitur warna HSV dan fuzzy decision tree ID3 menghasilkan nilai error yang lebih rendah.

Berdasarkan kesimpulan, diperlukan cahaya yang cukup terang untuk mendeteksi warna menggunakan game Finding Color. Sehingga disarankan user menggunakan game dengan kondisi pencahayaan yang baik. Oleh karena itu diharapkan pada penelitian selanjutnya dapat menambahkan fitur flash dalam game sehingga dapat membantu sistem mendeteksi warna dengan tepat dalam keadaan pencahayaan yang kurang. Selain itu disarankan agar penelitian 
selanjutnya menambah banyaknya warna berdasarkan tingkat kesulitan yang lebih beragam.

\section{DAFTAR PUSTAKA}

[1] C. Fajri, "Tantangan industri kreatif-game online di Indonesia," Jurnal Komunikasi, vol. 1, pp. 443-454, Juli 2012.

[2] N. Marlianti, "Penggunaan metode karyawisata untuk meningkatkan kemampuan mengenal warna pada anak tk", Skripsi Sarjana, Universitas Pendidikan Indonesia, Bandung, Indonesia, 2012.

[3] E. A. Pratama, "Alat peraga pengenalan warna bagi anak usia dini (studi kasus : TK bhinneka Surabaya)," Skripsi Sarjana, Universitas Narotama, Surabaya, Indonesia, 2017.

[4] R. Ariona, "Game edukasi pengenalan warna sebagai mediapembelajaran anak usia prasekolah berbasis android," Skripsi Sarjana, Jurusan Teknik Elektro, Fakultas Teknik, Universitas Negeri Semarang, Indonesia, 2014.

[5] S. D. H. Permana, "Pembangunan aplikasi game android pengenalan pola warna pada paud posdaya," Jurnal Infotel, vol. 7, no. 2, pp. 113-120, November 2015.

[6] J. A. Sidette, E. Sediyono, dan O. D. Nurhayati. "Pendekatan metode pohon keputusan menggunakan algoritma ID3 untuk sistem informasi pengukuran kinerja PNS”, Jurnal Sistem Informasi Bisnis, vol. 2, pp. 75-86, 2014.

[7] E. Handriyantini, "Permainan edukatif (educational games) berbasis komputer untuk siswa sekolah dasar," Konferensi dan Temu
Nasional Teknologi Informasi dan Komunikasi untuk Indonesia, 2009, pp.130-135.

[8] Henry, Cerdas dengan Game Panduan Praktis bagi Orangtua dalam Mendampingi Anak Bermain Game, Yogyakarta: Kompas Gramedia, 2010 .

[9] E. Hecht, Optics, 5th ed., Harlow, England: Pearson Education, 2017.

[10] Atun, H., R. Sinekli, dan U. Tekbas, "An efficient color detection in rgb space using hierarchical neural network structure", 2011 International Symposium on Innovations in Intelligent Systems and Applications (INISTA), 2011, pp. 154-158.

[11] K. Bernard, V. Cardei dan B. Funt, "A comparison of computational color constancy algorithms - part i: methodology and experiments with synthesized data," IEEE Transactions on Image Processing, vol. 11, no. 9, pp. 972-984, Sept. 2002.

[12] R. Munarto, E. Permata dan R. Salsabilla, "Klasifikasi kualitas biji jagung manis berdasarkan fitur warna menggunakan fuzzy logic," Simposium Nasional RAPI XIII, 2014, pp. E5-12.

[13] R. D. Suryawanshi dan D. M. Thakore, "Decision tree classification implementation with fuzzy logic," IJCSNS International Journal of Computer Science and Network Security, vol. 12, pp. 93-97, 2012.

[14] F. S. N. Khamidah, D. Hapsari dan H. Nugroho, "Implementasi fuzzy decision tree untuk prediksi gagal ginjal kronis," INTEGER: Journal of Information Technology, vol. 3, pp. 19-28, 2018.

[15] R. D. Kusumanto, A. N. Tompunu dan W. S. Pambudi. "Klasifikasi warna menggunakan pengolahan model warna HSV", Jurnal Ilmiah Elite Elektro, vol. 2, no. 2, pp. 83-87, 2011. 